\title{
O PAPEL DO SISTEMA DE CONTROLE GERENCIAL NA TRANSIÇÃO ENTRE ESTÁGIOS DO CICLO DE VIDA ORGANIZACIONAL EM UMA EMPRESA FAMILIAR
}

\section{THE ROLE OF MANAGEMENT CONTROL SYSTEMS IN TRANSITION BETWEEN STAGES OF THE ORGANIZATIONAL LIFE CYCLE IN A FAMILY BUSINESS}

\section{EL ROL DEL SISTEMA DE CONTROL GERENCIAL EN LA TRANSICIÓN ENTRE ETAPAS DEL CICLO DE VIDA ORGANIZACIONAL EN UNA EMPRESA FAMILIAR}

Recebido em: 26/02/2018

Avaliado em: 12/03/2019

Reformulado em:26/03/2019

Aceito para publicação em: 15/04/2019

Publicado em: 14/06/2019

Editor Responsável: Franciele Beck
Leide Vania Miranda Moreira ${ }^{1}$

Fábio Frezatti ${ }^{2}$

\section{RESUMO}

Esta pesquisa teve como objetivo compreender o papel do sistema de controle gerencial (SCG) na evolução dos estágios do Ciclo de Vida Organizacional (CVO), particularmente no que tange às transições entre estágios em uma empresa familiar brasileira. O estudo foi realizado por meio da abordagem de estudo de caso, em um grupo de empresas de origem familiar, com mais de 50 anos de existência, que tem passagem pelos diversos estágios do CVO. Entre as contribuições do caso, resulta a identificação de períodos de subestágios de transição, que embora citados como possíveis, não têm sido evidenciados e incluídos nos modelos ou estudos cross-sectionals. Isso ocorre especialmente, entre as fases do Crescimento para a Maturidade e da Maturidade para a Renovação com reorganizações estruturais, preparação e implementação de controles, onde os mecanismos do Sistema de Controle Gerencial agem como suporte e facilitadores ao oferecer novas ferramentas nos processos de planejamento e controle das operações que se tornam mais complexas conforme a empresa atinge os estágios mais avançados do CVO. Em termos de contribuições práticas, o trabalho agrega ao repertório de exemplos, trazendo reflexão e aprendizado para os gestores e empreendedores das empresas familiares sobre o papel do sistema de controle gerencial nas transições de estágios que através da compreensão do fenômeno podem adaptar o caso as mais diversas variações de configurações internas, de forma a gerenciar as operações e se preparar para os novos ciclos que as organizações percebam como mais desejáveis com implementação de mecanismos do SCG para atender as necessidades de informações em cada estágio do CVO.

Palavras-chaves: Sistema de Controle Gerencial. Ciclo de Vida Organizacional. Empresas Familiares. Estudo de Caso.

\footnotetext{
1 Mestre em Controladoria e Contabilidade pela Universidade de São Paulo; Doutorando em Controladoria e Contabilidade pela Universidade de São Paulo; E-mail: leide.mmoreira@usp.br.

2 Doutor e Livre-docente em Controladoria e Contabilidade pela Universidade de São Paulo; Professor Titular do Departamento de Contabilidade e Atuária da Universidade de São Paulo E-mail: frezatti @usp.br 


\begin{abstract}
This study aimed to understand the role of management control systems in the evolution at the stages of the Organizational Life Cycle (OLC), as result of a case study in a 50-year-old Brazilian familycontrolled business as it has transformed from a small business to one of the biggest groups of education in Brazil with transition in the various stages of OLC. The case demonstrated that there are transition time, called sub-stages not explicitly identified in the traditional models or cross sectional studies. This occurs between the phases of Growth for Maturity and Maturity for Revival with structural reorganizations, preparation and implementation of controls, where the mechanisms of the Management Control System act as support and facilitators by offering new tools in the planning and control processes of the operations that become more complex as the company reaches the more advanced stages of the Organizational Life Cycle. For practice, the study adds to the repertoire of examples bringing insights to the managers and entrepreneurs of family businesses on the role of the management control system in the stage transitions that through the understanding of the phenomenon they can be adapt the case to the its variations of internal configurations to manage operations and to prepare for the new cycles that the organizations perceive as more desirable with implementation of MCS mechanisms to meet the information needs at each stage of the OLS.
\end{abstract}

Keywords: Management Control Systems. Organizational Life Cycle. Family Business. Study Case.

\title{
RESUMEN
}

Esta investigación tuvo como objetivo comprender el papel del sistema de control gerencial en la evolución de las etapas del Ciclo de Vida Organizacional, particularmente en lo que se refiere a las transiciones entre pasantías en una empresa familiar brasileña. El estudio fue realizado a través del enfoque de estudio de caso, en un grupo de empresas de origen familiar, con más de 50 años de existencia, que tiene paso por las diversas etapas del CVO. Entre las contribuciones del caso, resultan de la identificación de períodos de sub-etapas de transición, no identificados de forma explícita en los estudios cross sectionals. Esto ocurre especialmente entre las fases del Crecimiento para la Madurez y la Madurez para la Renovación con reorganizaciones estructurales, preparación e implementación de controles, donde los mecanismos del Sistema de Control Gerencial actúan como soporte y facilitadores al ofrecer nuevas herramientas en el proceso de planificación y control de las operaciones que se vuelven más complejas conforme la empresa alcanza las etapas más avanzadas del Ciclo de Vida Organizacional. Para la práctica, el studio agrega al repertorio de ejemplos, trayendo reflexión y aprendizaje a los gestores y emprendedores de las empresas familiares sobre el papel del sistema de control gerencial, que a través de la comprensión del fenómeno, pueden adaptar el caso a las más diversas variaciones de configuraciones internas para gestionar las operaciones y prepararse para los nuevos ciclos que las organizaciones perciben como más deseables con la implementación de mecanismos del SCG para atender las necesidades de información en cada etapa del CVO.

Palabras clave: Sistema de control gerencial. Ciclo de vida organizacional. Empresas familiares. Estudios de caso.

\section{INTRODUÇÃO}

A teoria do ciclo de vida organizacional (CVO) tem sido objeto de estudo por diversos pesquisadores. Nos diversos modelos, as características das organizações são classificadas entre estágios, desde o Nascimento até a Morte, e ajudam na compreensão da evolução das organizações no ciclo de vida, sendo encontrados modelos com abordagens mais lineares e evolutivas (Churchill, \& Lewis, 1983; Greiner, 1998; Quinn, \& Cameron, 1983) e outros mais flexíveis (Lester, Parnell, \& Carraher, 2003; Miller, \& Friesen, 1984). 
No que tange às empresas familiares, quando se observa a importância econômica, estas representam a forma de negócios predominante ao redor do mundo (Ifera, 2003) e, em especial nos países em desenvolvimento, são consideradas como "motor" de suas economias (Carney, 2005). No entanto, estima-se que somente $30 \%$ das empresas familiares passam para a segunda geração e apenas 10\% sobrevivem até a terceira geração (Dyck et al., 2002; Hiebl, 2012).

Para sobreviverem e evoluírem em seus ciclos de vida, as organizações eventualmente enfrentam necessidade de mudanças (Greiner, 1998; Scott; Bruce, 1987), no entanto poucos trabalhos e questões de pesquisas relacionadas ao CVO foram endereçadas aos sistemas de controle gerencial (Auzair, \& Langfield-Smith, 2005; Beuren, \& Pereira, 2013; Carvalho et al., 2010; Chenhall, 2007; Moores, \& Yuen, 2001; Souza, Necyk, \& Frezatti, 2008), cabendo a reflexão quanto ao papel do SCG nas transições de estágios e no desenvolvimento das empresas familiares.

O grau de formalização e burocratização das empresas familiares pode se distinguir dependendo do grau de envolvimento familiar e estrutura de governança (Carney, 2005; Hiebl, 2012), sendo em geral mais centralizadas nos processos de decisão e, consequentemente menos formalizadas nos controles gerenciais, com menor propensão a considerar opiniões de terceiros em suas tomadas de decisões (Chrisman, Chua, \& Sharma, 2005). No entanto, os modelos tradicionais de CVO assumem como tipologia de negócio, com a separação entre propriedade e gestão, já no estágio da Maturidade, o que nas empresas familiares pode ser um pouco diferente.

Em muitos casos, a análise sobre a adoção dos mecanismos do Sistema do Controle Gerencial é simplificada, ignorando aspectos relevantes evolucionários de transição que podem levar muitos anos para se estabelecer, afetando as transições de estágios (Giovannoni, Maraghini, \& Riccaboni, 2011; Scott, \& Bruce, 1987) com pouca ênfase quanto a figura do fundador e envolvimento de membros da família na gestão, passagens de sucessão e motivações para a profissionalização (Morris et al., 1997).

As pesquisas anteriores na área de Contabilidade Gerencial que aplicaram modelos de CVO, sugerem que controles gerenciais, uso de informações gerenciais e outras ferramentas de gestão são diferentes em cada etapa do ciclo de vida (Auzair, \& Langfield-Smith, 2005; Frezatti et al., 2010; Kallunki, \& Silvola, 2008; Moores, \& Yuen, 2001; Su, Baird, \& Schoch, 2015). Assim, a necessidade de controles e sistemas gerenciais formais e mais estruturados para atender as demandas é maior conforme a empresa avança nas etapas do CVO devido ao aumento da complexidade nas operações (DEKKER et al., 2012), considerando-se o estágio do CVO como fator contingencial (Necyk, \& Frezatti, 2010; Souza, Necyk, \& Frezatti, 2008).

Apesar desses achados, a maioria dos estudos encontrados tiveram como abordagens privilegiadas cross-sectionals (Auzair, \& Langfield-Smith, 2005; Frezatti et al., 2010; Granlund, \& Taipaleenmäki, 2005; Kallunki, \& Silvola, 2008; Moores, \& Yuen, 2001; Silvola, 2008; Su, Baird, \& Schoch, 2015) e não foram abordados os aspectos das mudanças no SCG como pacote nas transições entre os estágios do CVO (Kallunki, \& Silvola, 2008), sem entendimento claro de como as ferramentas evoluem historicamente (Miller, \& Friesen, 1984), sendo que as análises anteriores foram medidas entre o porte da empresa e o nível de existência ou forma de uso de controles gerenciais específicos, todas no mesmo tempo, sem consideração quanto aos períodos de transição e às motivações e dinâmicas da gestão familiar e da contabilidade gerencial quanto ao papel do SCG como condicionante nas mudanças de etapas do CVO (Necyk, \& Frezatti, 2010).

Silvola (2008) sugere a investigação de controles gerenciais no ciclo de vida com a abordagem de estudo de caso, a fim de contribuir de maneira mais profunda, rica e holística para o entendimento das pesquisas que se basearam nos métodos surveys, inclusive com a abordagem longitudinal para compreender os mecanismos do SCG adotados durante as transições de estágios (Moores, \& Mula, 2000).

Desta forma, considerando que para transitar pelas diversas fases do CVO, as ferramentas do SCG se fazem necessárias no acompanhamento e direcionamento dos objetivos, este trabalho visa avançar na compreensão da evolução e papel do SCG nas transições dos estágios do CVO de uma 
empresa familiar, ao discutir a seguinte questão de pesquisa: Como o sistema de controle gerencial evolui dando suporte às transições de estágios do Ciclo de Vida Organizacional na empresa familiar?

Para responder à questão de pesquisa e atingir o objetivo de compreender o papel do sistema de controle gerencial nas transições entre estágios do CVO, a metodologia do trabalho escolhida foi o estudo de caso único, tendo como objeto de estudo uma organização familiar brasileira, no qual foi analisada a sua evolução desde seu Nascimento até a fase atual, baseado no modelo de CVO de Miller e Friesen (1984). Em paralelo, a cada estágio identificado, discute-se quanto à evolução dos mecanismos do SCG baseados no mapeamento do modelo de Malmi e Brown (2008).

Quanto às contribuições para a perspectiva teórica, este trabalho traz a identificação dos períodos de transição, os subestágios, pouco abordados nos modelos cross-sectionals (Lester, Parnell, \& Carraher, 2003), onde observa-se crises de passagem e a evolução do Sistema de Controle Gerencial, trazendo a visão de seus antecedentes, as motivações e circunstâncias das mudanças na empresa familiar.

Para o conhecimento empírico, o estudo traz a perspectiva da contabilidade gerencial, envolvendo o papel do SCG como pacote na transição entre etapas, de forma a se tornar possível a passagem para os próximos estágios, complementando as outras variáveis contingenciais nos diversos estudos que aplicaram a teoria do CVO, inclusive com a visão do Controle Cultural.

Quanto às contribuições práticas, o estudo agrega ao repertório de exemplos quanto ao desenvolvimento das empresas familiares, trazendo a discussão do SCG como pacote que podem ter influenciado na evolução dos estágios da empresa familiar, reflexão sobre os papéis dos gestores e de membros familiares e aprendizado que podem ser adaptados, de acordo com as diversas variações, no sentido de orientar no processo decisório ao longo dos estágios evolutivos das organizações familiares e se preparar para os ciclos que a empresa perceba como desejáveis. Nesse sentido, entender as mudanças que ocorrem nas organizações e adotar controles gerenciais que proporcionam assertividade e direcionamento para o processo de gestão.

\section{REVISÃO DA LITERATURA}

\subsection{Empresas Familiares e Sistema de Controle Gerencial}

Chrisman, Chua e Sharma (2005) caracterizam a empresa familiar em quatro pontos na literatura: i) a influência da família na direção estratégica da empresa; ii) a intenção da família em se manter no controle da empresa; iii) comportamento como empresa familiar, incluindo o desejo e a visão de se sustentar e passar por diversas gerações preservando seus valores; iv) recursos únicos, inseparáveis e sinergéticos, e capacidade ou competências que se estabeleceram na empresa pela integração e envolvimento da família. Eles denominam esse conjunto de essência.

O grau de envolvimento da família de forma a influenciar os negócios, seja na propriedade, seja na gestão ou governança, é o requisito convergente e está em todas as definições de empresa familiar (Dawson, Mussolino, 2014). A cultura corporativa da empresa familiar também representa uma característica particular devido à sobreposição dos valores familiares com os valores da companhia (Songini, Gnan, \& Malmi, 2013).

Com a busca da integração da vida familiar nos negócios e consideração de fatores de apego socioemocionais, o estilo da tomada de decisões e o gerenciamento das atividades do dia a dia são diferentes das empresas não familiares (Kalm, Gomez-Mejia, 2016), impactando controles culturais e de clãs, pois são mais centralizadas, flexíveis e menos burocráticos, com menor formalização nos controles gerenciais (Acquaah, 2013).

No entanto, durante as passagens dos estágios do CVO, as empresas familiares enfrentam necessidades de mudanças para superar eventuais crises (Scott, \& Bruce, 1987). As práticas gerenciais que funcionam bem em uma fase e fazem com que a organização evolua em crescimento e estabilidade, chamados de estágios de evolução, num determinado momento chegam em seu limite, provocando os estágios de revolução. Essas crises provocam mudanças, inclusive com a adição de 
novas abordagens, que fazem com que as empresas procurem novas práticas gerenciais para passar para a próxima fase (Greiner, 1998).

O SCG aliado às mudanças traz ferramentas importantes para o processo de planejamento e alcance das metas de empresas, com isso, naturalmente se enquadra na empresa familiar, com a diferença de que estas são trabalhadas entre executivos contratados fora da família e executivos que fazem parte da família. Isso pode aumentar a possibilidade de conflitos, diferentes usos e perspectivas em relação a uma empresa não familiar (Acquaah, 2013).

O planejamento do processo sucessório e profissionalização necessários são questões importantes para a continuidade da empresa familiar (Dyck et al., 2002). Portanto, essa preocupação é continua, estratégica e complexa na vida das empresas e, com o passar do tempo aumenta a importância da formalização para manter a estabilidade da gestão. É aqui que o SCG tem, cada vez mais, sua relevância.

O processo sucessório é dividido em dois tipos: a sucessão familiar e a sucessão profissional (Morris et al., 1997). A profissionalização acontece quando executivos, da família ou não, preparados profissionalmente, passam a ocupar cargos diretivos da empresa familiar. A organização deve lidar com graus diferentes de profissionalização, com menor ou maior abertura a cargos de gestão para membros não familiares, e diferentes níveis de adoção e formalização dos mecanismos do SCG e estrutura de governança (Dekker et al., 2012), representando também um aspecto importante do ponto de vista da Contabilidade Gerencial (Songini, Gnan, \& Malmi, 2013).

\subsubsection{Sistema de Controle Gerencial}

De acordo com Simons (1995), o Sistema de Controle Gerencial é composto por rotinas e procedimentos formais, baseados em informações que os gestores usam para manter ou alterar o percurso das atividades organizacionais. Esses procedimentos podem ser exemplificados com o orçamento, balanced scorecard, planejamento estratégico e sistemas de avaliação de desempenho.

O modelo de sistema de controle gerencial baseado em Simons (1995) consiste em quatro níveis de controle, que funcionam como forças opostas necessárias que criam dinâmicas de tensões para assegurar o controle efetivo compostos pelos Sistema de Crenças e Sistemas de Controles Interativos e pelos Sistema de Limite e Sistemas de Controles Diagnósticos. Este modelo foca na intensidade do uso formal de controles pelos gestores e subordinados (Ferreira, \& Otley, 2009; Tessier, \& Otley, 2012).

Por sua vez, Ferreira e Otley (2009) entendem o SCG como processos formais e informais, envolvendo mecanismos, sistemas e artefatos usados pelas organizações para assistir no processo estratégico, por meio de análises, planejamento e controle e acompanhamento de performance, de forma a suportar e avaliar os objetivos traçados pela companhia, como também facilitar o aprendizado organizacional e mudanças. Agregam à abordagem de Simons (1995) tanto na explicitude da importância dos controles informais como foco estrutural dos mecanismos.

A separação por foco de controle é a contribuição do modelo de Malmi e Brown (2008), especificando tipos de controle como administrativo e cultural, complementando os controles e rotinas formais no controle das atividades e direcionamento da performance organizacional. Segundo os autores, SCG são práticas e outras atividades que os gestores utilizam para direcionar o comportamento dos empregados.

Desta forma, o modelo de Malmi e Brown (2008), foi o escolhido pois contém um mapeamento dos controles e tipologia baseada em um pacote categorizado em cinco grupos, apresentados na tabela a seguir, pois o foco deste estudo, está na identificação e nos tipos de controles do SCG durante as etapas do CVO, incluindo controles formais e informais que predominam nos estágios iniciais nas empresas familiares. 
Quadro 1 - Resumo do Modelo de SCG de Malmi e Brown (2008)

\begin{tabular}{|c|c|}
\hline Tipo de Controle & Foco e função do controle \\
\hline Planejamento & $\begin{array}{l}\text { Na etapa do Planejamento, a organização estabelece metas para as áreas funcionais, direcionando } \\
\text { esforços e comportamentos individuais e em equipe de forma a atingir os resultados desejados. } \\
\text { Podem ter metas financeiras ou qualitativas, e podem ser criados projetos estratégicos e outras } \\
\text { iniciativas. }\end{array}$ \\
\hline $\begin{array}{l}\text { Controles } \\
\text { Cibernéticos }\end{array}$ & $\begin{array}{l}\text { Os controles cibernéticos são sistemas usados para mensuração de performance e comparação com } \\
\text { as metas definidas, monitoramento das informações sobre as variações não desejadas como o } \\
\text { orçamento, indicadores financeiros e não financeiros. }\end{array}$ \\
\hline $\begin{array}{lr}\text { Sistema } & \text { de } \\
\text { Remuneração } & \text { e } \\
\text { Recompensa } & \end{array}$ & $\begin{array}{l}\text { O sistema de remuneração e recompensas foca em motivar e aumentar os esforços da performance } \\
\text { individual e em equipe pela congruência dos objetivos e atividades com os da organização } \\
\text { incluindo a direção dos esforços, o foco das atividades e a intensidade do quanto de atenção é } \\
\text { dedicada às tarefas. }\end{array}$ \\
\hline $\begin{array}{l}\text { Co } \\
\text { adi }\end{array}$ & $\begin{array}{l}\text { Direcionam os comportamentos de indivíduos e grupos da organização em relação a processos e } \\
\text { tarefas a serem cumpridas. Incluem estrutura e desenho organizacional, encorajando os tipos de } \\
\text { contatos e relacionamentos, estrutura de governança corporativa representando as várias funções e } \\
\text { unidades de negócio, coordenando as atividades horizontal e verticalmente; políticas e } \\
\text { procedimentos sobre processos, regras e práticas de comportamento na organização, como, por } \\
\text { exemplo, alçada de aprovação de despesas. }\end{array}$ \\
\hline & $\begin{array}{l}\text { Referem-se ao conjunto de valores, crenças e normas sociais compartilhadas entre os membros de } \\
\text { forma a influenciar pensamentos e ações. Podem ser baseados em valores e símbolos: (i) em valores } \\
\text { são comunicados formalmente e reforçados sistematicamente sobre os propósitos e direção da } \\
\text { organização, cuja expectativa da alta direção é de seguimento por parte dos subordinados, como } \\
\text { exemplo a missão, visão, gerando impacto na contratação de empregados com mesmos valores, } \\
\text { mudança dos valores dos empregados para se adequar aos da organização ou explicados para se } \\
\text { adequarem, mesmo que pessoalmente não compartilhados, mas para que se comportem como tal; } \\
\text { (ii) controle baseado em símbolos são expressões visíveis no ambiente de trabalho como layout do } \\
\text { escritório e uso de uniforme. Controle de clãs são subculturas ou microculturas ou grupo de } \\
\text { indivíduos como, por exemplo, profissional (médicos, contadores, professores, etc.) com processo } \\
\text { de socialização, conjunto de habilidades, valores e crenças próprios. }\end{array}$ \\
\hline
\end{tabular}

Fonte: Os autores

\subsection{Ciclo de Vida Organizacional}

Lester e Parnell (2008) listam diversos autores que desenvolveram modelos sobre o Ciclo de Vida Organizacional, datados desde 1952, buscando compreender as etapas de desenvolvimento das organizações, desde modelos mais orientados para pequenas organizações (Churchill, \& Lewis, 1983; Scott, \& Bruce, 1987), e até os voltados para grandes empresas (Greiner, 1998; Miller, \& Friesen, 1984).

Greiner (1972, republicado em 1998) foi um dos primeiros autores a elaborar um modelo conceitual de CVO. O modelo foi construído com base em experiências e observações do próprio autor, mas de importância no desenvolvimento de modelos seguintes com base empírica (Churchill, \& Lewis, 1983; Quinn, \& Cameron, 1983; Miller, \& Friesen, 1984; Lester, Parnell, \& Carraher, 2003; Scott, \& Bruce, 1987).

O modelo de Miller e Friesen (1984), que foi escolhido para este estudo, se distingue pela abordagem longitudinal, no qual um conjunto de 36 empresas foram analisadas para uma amostra de 161 períodos, de modo a traçar as características de vários tipos de segmentos e estruturas das organizações nos diversos estágios com relação à influência e descrição das seguintes variáveis contingenciais: estratégia, estrutura, contexto e estilo de tomada de decisões.

O quadro 2 detalha o modelo de Miller e Friesen (1984), com a classificação nos cinco estágios: Nascimento, Crescimento, Maturidade, Renovação e Declínio.

O modelo apresenta uma estrutura possível para analisar uma empresa em diversos períodos de forma retrospectiva, ao investigar as características da empresa de forma histórica, além da consideração da formalização de controles para tomada de decisões em cada etapa do CVO. O estudo de Miller e Friesen (1984), por ser longitudinal, também permitiu aos autores constatar que a evolução 
dos estágios pode ser flexível, e a empresa pode estar no estágio da Renovação ou Declínio e voltar para a Maturidade.

Quadro 2 - Resumo Modelo de Ciclo de Vida Organizacional de Miller e Friesen (1984)

\begin{tabular}{|c|c|c|}
\hline Fase e Situação & Estrutura & Estratégias / Estilo de tomada de decisões \\
\hline $\begin{array}{l}\text { Nascimento: } \\
\text { A empresa tem até } 10 \text { anos. } \\
\text { Novas e pequenas em } \\
\text { relação aos concorrentes. } \\
\text { Concentração de poder e } \\
\text { decisão nos proprietários. }\end{array}$ & $\begin{array}{l}\text { Simples e centralizada. Dirigida } \\
\text { pelos donos. } \\
\text { Atividades administrativas } \\
\text { simples com poucos controles } \\
\text { formais ou uso mínimo de } \\
\text { sistemas de informações. }\end{array}$ & $\begin{array}{l}\text { Busca viabilidade do negócio. Pró-atividade no } \\
\text { desenvolvimento de produtos e serviços. Geração de } \\
\text { competências. Riscos substanciais. Decisões } \\
\text { baseadas em intuição, sem análise detalhada de } \\
\text { projetos ou consideração de alternativas. }\end{array}$ \\
\hline $\begin{array}{l}\text { Crescimento: } \\
\text { Empresa já tem } \\
\text { estabilidade no mercado e } \\
\text { demonstra potencialidade } \\
\text { do negócio. Maiores que na } \\
\text { fase anterior. Maior } \\
\text { heterogeneidade do } \\
\text { ambiente externo. }\end{array}$ & $\begin{array}{l}\text { Estrutura funcional } \\
\text { departamental. } \\
\text { Mais complexa e descentralizada } \\
\text { que na fase anterior. Maior } \\
\text { formalização e processamento de } \\
\text { informações, monitoramento e } \\
\text { controle. }\end{array}$ & $\begin{array}{l}\text { Busca crescimento com diversificação e inovação no } \\
\text { range de produtos. Tomada de decisões mais } \\
\text { analíticas e integradas, racionais e baseadas em } \\
\text { informações, como por exemplo, performance } \\
\text { financeira dos produtos. }\end{array}$ \\
\hline $\begin{array}{l}\text { Maturidade: } \\
\text { Maiores e mais velhas que } \\
\text { nas fases anteriores. } \\
\text { Possuem vantagem } \\
\text { competitiva sobre os } \\
\text { concorrentes. } \\
\text { Menor grau de incerteza do } \\
\text { ambiente externo. }\end{array}$ & $\begin{array}{l}\text { Departamentalização, funcional, } \\
\text { gerenciada por profissionais } \\
\text { especializados. Maior controle } \\
\text { de custos, uso do orçamento e } \\
\text { indicadores de desempenho. } \\
\text { Direção centralizada em poucos } \\
\text { gestores. }\end{array}$ & $\begin{array}{l}\text { Maior aversão a risco, mais conservadora, foco em } \\
\text { controle de custos, e margens de lucros. } \\
\text { Tomada de decisão nas mãos de poucos diretores } \\
\text { devido a estabilidade e simplicidade das operações. } \\
\text { No entanto, há maior peso na análise de alternativas, } \\
\text { procura pela produtividade e eficiência. }\end{array}$ \\
\hline $\begin{array}{l}\text { Renovação: } \\
\text { Maiores que nas fases } \\
\text { anteriores, ambiente mais } \\
\text { heterogêneo, dinâmico e } \\
\text { hostil. } \\
\text { Necessidades dos clientes } \\
\text { acima das dos membros da } \\
\text { organização. }\end{array}$ & $\begin{array}{l}\text { Estrutura divisional. } \\
\text { Descentralizada e maior } \\
\text { autonomia operacional por } \\
\text { divisões. Sistemas sofisticados } \\
\text { para monitorar performance das } \\
\text { divisões. Maior processamento } \\
\text { de informações. }\end{array}$ & $\begin{array}{l}\text { Maior foco por inovação, diversificação e expansão } \\
\text { de produtos e mercados, com maiores riscos, } \\
\text { revertendo a inércia da Maturidade. Tomada de } \\
\text { decisões de forma reflexiva, analítica e participativa, } \\
\text { devido a maior propensão a risco e análise do } \\
\text { ambiente (oportunidades e ameaças). Planejamento e } \\
\text { foco na evolução futura da empresa. }\end{array}$ \\
\hline $\begin{array}{l}\text { Declínio: } \\
\text { Estagnação, sem estratégia } \\
\text { definida. } \\
\text { Necessidades dos donos, } \\
\text { acima da dos clientes. } \\
\text { Ambiente hostil. }\end{array}$ & $\begin{array}{l}\text { Tamanho pode ser similar à } \\
\text { maturidade, porém simples e } \\
\text { centralizada. Falta de controles } \\
\text { formais e mecanismos de } \\
\text { processamento de informações } \\
\text { ou abandono destes. }\end{array}$ & $\begin{array}{l}\text { Conservadora, sem uso das informações e análises } \\
\text { para tomada de decisões, foco no curto prazo. Falta } \\
\text { de planejamento estratégico. }\end{array}$ \\
\hline
\end{tabular}

Fonte: Os autores

Nos trabalhos internacionais, tem sido o modelo mais utilizado nas pesquisas em Contabilidade Gerencial (Granlund; Taipaleenmäki, 2005) e testado por diversos trabalhos empíricos (Auzair, \& Langfield-Smith, 2005; Kallunki, \& Silvola, 2008; Moores, \& Yuen, 2001; Silvola, 2008; Su, Baird, \& Schoch, 2015).

O quadro 3, demonstra os resultados de pesquisas em Contabilidade Gerencial que abordaram a teoria de Ciclo de Vida Organizacional. Em seguida são apresentados alguns dos estudos empíricos nacionais. Foram encontradas também pesquisas bibliográficas e levantamentos de artigos identificando-se os principais trabalhos e lacunas alinhados com este estudo (Beuren, \& Pereira, 2013; Beuren, Rangel, \& Rodrigues Junior, 2015; Carvalho et al, 2010; Cunha, Klan, \& Lavarda, 2013).

Entre os estudos nacionais, Frezatti et al. (2010) investigaram a existência de controles gerenciais durante as etapas do CVO do modelo de Lester, Parnell e Carraher (2003) em empresas de médio porte brasileiras, e concluíram que estes não são homogêneos, podendo influenciar a 
capacidade de evolução e crescimento das empresas que não utilizam tais ferramentas para suporte de sua gestão e tomada de decisão.

Quadro 3 - Principais trabalhos com a abordagem do CVO na área de Contabilidade Gerencial

\begin{tabular}{|c|c|c|c|}
\hline Autores & Objetivo e escopo da pesquisa & $\begin{array}{l}\text { Método/ } \\
\text { Amostra }\end{array}$ & Resultados e Conclusões \\
\hline $\begin{array}{l}\text { Moores \& Mula } \\
(2000)\end{array}$ & $\begin{array}{l}\text { Identificar a existência de } \\
\text { controles burocráticos e } \\
\text { controles de clãs conforme } \\
\text { modelo de Ouchi (1979) nos } \\
\text { estágios do CVO de Quinn e } \\
\text { Cameron (1983). }\end{array}$ & $\begin{array}{l}278 \text { empresas } \\
\text { familiares } \\
\text { (Austrália) }\end{array}$ & $\begin{array}{l}\text { Nas primeiras fases predominam-se os } \\
\text { controles informais e a adição de controles } \\
\text { formais em estágios mais avançados. Nos } \\
\text { entanto, mecanismos formais e informais } \\
\text { coexistem nos estágios mais avançados. }\end{array}$ \\
\hline $\begin{array}{l}\text { Moores \& Yuen } \\
(\mathbf{2 0 0 1 )}\end{array}$ & $\begin{array}{l}\text { Identificar atributos de } \\
\text { informação dos sistemas de } \\
\text { contabilidade gerencial durante } \\
\text { o ciclo de vida das } \\
\text { organizações. }\end{array}$ & $\begin{array}{l}\text { Cluster, } \\
49 \text { empresas } \\
\text { (Austrália) e } \\
\text { entrevistas }\end{array}$ & $\begin{array}{l}\text { A formalização das informações aumenta dos } \\
\text { estágios do nascimento para o crescimento, } \\
\text { decresce no estágio da maturidade e aumenta } \\
\text { no estágio da renovação. }\end{array}$ \\
\hline $\begin{array}{l}\text { Auzair } \\
\text { \&Langfield- } \\
\text { Smith (2005) }\end{array}$ & $\begin{array}{l}\text { Identificar a influência de } \\
\text { variáveis contingenciais na } \\
\text { escolha de mecanismos de } \\
\text { controle. }\end{array}$ & $\begin{array}{l}\text { Survey, } \\
121 \text { empresas } \\
\text { de serviços } \\
\text { (Austrália) } \\
\end{array}$ & $\begin{array}{l}\text { Tipo de serviço, escolha estratégia e estágio do } \\
\text { CVO influenciam na escolha de controles } \\
\text { formais. }\end{array}$ \\
\hline Silvola (2008) & $\begin{array}{l}\text { Aplicação do CVO para } \\
\text { relacionar com a estrutura de } \\
\text { capital e nível de uso de } \\
\text { controles referente a } \\
\text { planejamento, orçamento e } \\
\text { técnicas de controle gerencial. }\end{array}$ & $\begin{array}{l}\text { Survey, } \\
105 \text { empresas } \\
\text { Finlândia }\end{array}$ & $\begin{array}{l}\text { Nas fases da maturidade e renovação há maior } \\
\text { uso de capital de investidores externos e } \\
\text { consequentemente maior necessidade de } \\
\text { controles para gerenciamento de informações } \\
\text { para maior número de investidores. }\end{array}$ \\
\hline $\begin{array}{l}\text { Kallunki \& } \\
\text { Silvola (2008) }\end{array}$ & $\begin{array}{l}\text { Análise dos efeitos dos estágios } \\
\text { do CVO e o sistema de custeio } \\
\text { ABC. }\end{array}$ & $\begin{array}{l}\text { Survey, } 105 \\
\text { empresas } \\
\text { Finlândia }\end{array}$ & $\begin{array}{l}\mathrm{O} \text { uso do } \mathrm{ABC} \text { é mais frequente nas fases da } \\
\text { maturidade e renovação. }\end{array}$ \\
\hline $\begin{array}{l}\text { Giovannoni et al } \\
(2011)\end{array}$ & $\begin{array}{l}\text { Estudaram as características da } \\
\text { contabilidade gerencial em uma } \\
\text { empresa familiar em relação } \\
\text { aos processos de sucessão e } \\
\text { profissionalização. }\end{array}$ & $\begin{array}{l}\text { Estudo de caso } \\
\text { longitudinal, } \\
\text { empresa } \\
\text { familiar (Itália) }\end{array}$ & $\begin{array}{l}\text { A contabilidade gerencial pode ajudar na } \\
\text { transferência de conhecimento entre gerações e } \\
\text { entre fundador e gestores. }\end{array}$ \\
\hline $\begin{array}{l}\text { Su, Baird, \& } \\
\text { Schoch }(2015)\end{array}$ & $\begin{array}{l}\text { Análise da relação entre os } \\
\text { estágios do CVO e usos do } \\
\text { SCG entre interativo e } \\
\text { diagnóstico (Simons, 1995) e a } \\
\text { associação com a performance } \\
\text { organizacional. }\end{array}$ & $\begin{array}{l}\text { Survey, } 343 \\
\text { empresas } \\
\text { Austrália }\end{array}$ & $\begin{array}{l}\text { Uso interativo tem relação positiva com a } \\
\text { performance no estágio do nascimento e } \\
\text { negativa no renovação. Uso diagnóstico tem } \\
\text { relação positiva no estágio da renovação e } \\
\text { negativa na maturidade. }\end{array}$ \\
\hline
\end{tabular}

Fonte: Os autores

Klan et al. (2012) analisaram o relacionamento entre os estágios de ciclo de vida do modelo de Miller e Friesen (1984) e o processo de planejamento de empresas metalúrgicas em Brusque-SC, a partir de uma amostra de 30 empresas. Os resultados indicaram adoção de planejamento estratégico na fase da maturidade, enquanto o orçamento e controle orçamentário não apresentaram relação significativa. Já no estágio da Renovação, os controles foram encontrados com maior frequência.

Faveri et al. (2014) encontraram resultados semelhantes com o modelo de Miller e Friesen (1984) na amostra de 116 empresas prestadoras de serviços contábeis em Santa Catarina. Lavanda e Pereira (2012) pesquisaram o uso dos sistemas de gestão em empresas emissoras de rádio, usando o modelo de Lester et al. (2003), e a amostra das 22 empresas indicou uso do sistema interativo à medida em que as empresas passam do estágio do crescimento para a maturidade. 


\section{METODOLOGIA DE PESQUISA}

A abordagem metodológica da pesquisa é de caráter qualitativo tendo, como estratégia de pesquisa, o estudo de caso. Segundo Ahrens e Chapman (2006), a pesquisa qualitativa é diferenciada pelo conhecimento do campo, sujeito a diversas interpretações e que somente faz sentido com referência a uma teoria que ilumine as atividades.

Assim, o estudo de caso é apropriado na investigação de questões particulares e individuais, contribuindo para conhecimento dos fenômenos organizacionais, no seu mundo real, quando a situação é complexa e envolve diversas variáveis, variáveis essas não quantitativas e quando não é claro o relacionamento entre elas (Cooper, \& Morgan, 2008; Marques, Camacho, \& Alcantara, 2015; Yin, 2014).

A avaliação qualitativa do estudo de caso é caracterizada pela descrição, compreensão e interpretação de fatos e fenômenos (Martins, \& Theóphilo, 2009). O estudo de caso pode ter perspectiva longitudinal, tratando dois ou mais pontos diferentes do tempo, explicando mudanças, acontecimentos e processos ao longo do tempo (Yin, 2014) como é o caso deste estudo ao explorar as mudanças organizacionais desde a fundação da empresa até o momento da pesquisa.

O pedido para permissão de acesso à empresa foi feito à pró-reitora de uma das instituições e ao diretor financeiro do grupo, no qual foi entregue e assinada uma carta formal expondo a proposta da pesquisa, descrevendo os procedimentos, compromissos e garantia de confidencialidade que foi enviada aos demais entrevistados para obtenção de seus consentimentos para entrevistas.

\subsection{Objeto da Pesquisa}

A empresa, objeto de estudo, é um grupo empresarial de grande porte, de origem familiar, atuante de forma crescente no Brasil, que, através de suas controladas diretas e indiretas, atua na prestação de ensino em todos os níveis educacionais. Semelhante a outras instituições, a história do grupo começou em meados da década de 60, com apenas duas salas de aula.

A empresa cresceu, surgiu a faculdade, transformando-se em Universidade na década de 90, expandiu-se e é hoje é um dos maiores conglomerados de educação no país, sendo a idade e porte fatores importantes, pois indicam a possibilidade de passagem pelos diversos estágios do CVO, uma vez que a pesquisa visa contemplar a evolução do SCG nas transições dos estágios, e ao estudar diferentes períodos no tempo, ser possível capturar o processo de transição da instituição durante as diversas fases.

No momento do contato para a pesquisa, duas das famílias remanescentes possuem cerca de $60 \%$ das ações (Famílias A e B). Desde os anos 2000, após planejamento sucessório, apenas um membro sucessor de cada uma das duas famílias, faz parte da diretoria executiva juntamente com o fundador (Família A), que exerce a função de presidente, não havendo outros membros familiares trabalhando na instituição.

O Conselho de Administração era composto por membros de ambas as famílias (fundador, conjugues e filhos), acionistas investidores participantes como sócios investidores private equity, além de acionistas minoritários, resultantes de combinações de negócio, estes sem direito a voto. O número de funcionários era cerca de 4.100, com $83 \%$ dos funcionários nas Instituições de Ensino e $17 \%$ de funcionários alocados nas áreas de suporte ao negócio, como Administrativo e Financeiro, Marketing e Comercial.

\subsection{Método de coleta dos dados}

Para a construção dos dados, foram utilizadas as seguintes técnicas: entrevistas, observação e análise de documentos. As primeiras entrevistas foram realizadas com o diretor financeiro, responsável pela área de controladoria e administrativa e a gerente de recursos humanos. Tiveram por objetivos entender a estrutura, situação organizacional do grupo no momento atual, os controles 
gerenciais atualmente utilizados, levantamento do organograma, identificação de pessoas chaves e permissão para novas entrevistas.

Posteriormente, foram realizadas novas entrevistas com o diretor financeiro e com um dos dois executivos familiares da segunda geração envolvidos na gestão. Todas as entrevistas ocorreram dentro das instalações do grupo e sempre que possível foram gravadas após permissão dos participantes. Quadro 4 lista a distribuição dos entrevistados.

Quadro 4 - Informações sobre os entrevistados

\begin{tabular}{|c|c|c|c|}
\hline Entrevistado(a) & Cargo & Data & Duração total \\
\hline Sujeito 1 & Diretor financeiro (profissional) & Março/ 2016 e Outubro/2016 & $3 \mathrm{~h}$ \\
\hline Sujeito 2 & Gerente de Recursos Humanos & Abril/2016 & $1,5 \mathrm{~h}$ \\
\hline Sujeito 3 & Diretor executivo (membro familiar) & Outubro/2016 & $2 \mathrm{~h}$ \\
\hline Sujeito 4 & Analista de controladoria & Outubro/2016 & $2 \mathrm{~h}$ \\
\hline
\end{tabular}

Fonte: Os autores

Dos quatro entrevistados, dois são diretores executivos, sendo o diretor financeiro estatutário, na empresa desde 2008, tendo presenciado e participado das mudanças estruturais do grupo nos últimos anos, incluindo o processo para preparação de aporte de investidores private equity. A Diretoria Financeira e Administrativa engloba a área de Controladoria contemplando Orçamento e Planejamento, Contabilidade e Fiscal, Tesouraria, Administrativa (facilidades), Jurídico, Tecnologia e Informação, e Recursos Humanos.

O diretor executivo membro familiar, é sucessor do fundador da Família A, a cargo das estratégias da empresa desde os anos 2000. Dos funcionários, a entrevistada que foi indicada atua na área de controladoria, na empresa há 24 anos (desde 1991), e pôde relatar as mudanças organizacionais e sua experiência, relacionadas à evolução e implantação dos controles gerenciais e percepção sobre o desenvolvimento da empresa ao longo dos anos.

As entrevistas semiestruturadas foram baseadas nas variáveis de Miller e Friesen (1984) questionando-se quanto a história evolutiva da empresa desde a fundação referente as estratégias da empresa, situação organizacional, estrutura e estilo de tomada de decisões e quanto a existência dos tipos de mecanismos gerenciais do modelo de Malmi e Brown (2008) desde o Nascimento da empresa até Outubro/2016, quando da finalização da pesquisa de campo. Os entrevistados foram questionados quanto: aos atributos dos mecanismos, abrangência, frequência e percepção de utilidade, assim como impactos no dia a dia no direcionamento das atividades e na tomada de decisões.

De forma a complementar a coleta de dados, outros métodos foram usados para comparação e análise, afim de aumentar o rigor metodológico exigido em um estudo de caso (Yin, 2014). Especificamente, o acesso às instalações das empresas e ao ambiente era frequente devido ao vínculo de um dos autores a uma das instituições. Portanto, devido à participação no dia a dia da empresa, contato com funcionários, acesso ao ambiente, reuniões, memorandos, artefatos, ficaram próximos, permitindo-se formar observações gerais sobre a história, controles gerenciais, e observações do contexto, cultura, valores e filosofia da empresa (De Massis, \& Kotlar, 2014).

Foram obtidos documentos internos da empresa, como livro da empresa de edição comemorativa com fotografias, depoimentos, história dos fundadores, e principais eventos sobre sua história desde a fundação até o ano de 2003, incluindo reorganizações societárias, plano de sucessão e abertura de profissionalização; manuais e políticas e procedimentos internos; e outras informações de comunicação interna, além de manuscritos dos entrevistados e observação presencial de relatórios da diretoria e do conselho.

Outros documentos públicos incluem-se as demonstrações contábeis juntamente com as notas explicativas auditadas por Auditoria Independente a partir do ano de 2011, nos quais se retrata parte das reorganizações societárias, aquisições e combinações de negócios a partir dos anos 2000. Foram 
consultados também notícias da mídia sobre a instituição e o mercado de atuação, e o website da companhia e das empresas controladas.

Essa combinação de dados permitiu confirmar eventos relevantes no desenvolvimento e estrutura da organização. Para controle de documentos coletados e dados construídos, foi criada uma pasta para armazenagem de arquivos, gravações das entrevistas e anotações das entrevistas e observações, assim como documentos coletados. No entanto, obedecendo o compromisso de confidencialidade, será eliminada qualquer referência ao nome da empresa ou aos seus profissionais.

\subsection{Análise dos Dados}

Para a análise dos dados de forma longitudinal, foi elaborado um documento em Excel, com informações históricas em ordem cronológica, desde a formação da empresa até o ano de 2016, para classificação da empresa nos diversos estágios do CVO, com base nas características homogêneas da empresa nos diferentes períodos, constatando-se as mudanças marcantes com base nas variáveis e modelo Miller e Friesen (1984), referente a quatro categorias: situação organizacional, estrutura organizacional, estratégias e estilo de tomada de decisões.

Essas informações foram construídas triangulando-se os relatos das entrevistas pessoais, análise das documentações e anotações de campo oriundas das observações em campo que incluíram depoimentos de outros funcionários de diferentes funções sobre suas percepções quanto à trajetória da empresa e impactos do sistema de controle gerencial em suas rotinas.

As variáveis consideradas quanto à situação organizacional são: idade, tamanho da empresa em número de alunos e funcionários, concentração e influência dos donos e proprietários nas decisões estratégicas e operacionais que tendem a diminuir conforme a empresa passa pelas quatro primeiras fases. O dinamismo, hostilidade e heterogeneidade do ambiente aumentam conforme a empresa expande o range de produtos e serviços (Miller, \& Friesen, 1984).

Pela idade da empresa, tamanho, número de funcionários e por se posicionar entre as 10 primeiras no seu ramo de atuação, a etapa atual como Nascimento está descartada, assim como o estágio do Declínio foi descartado durante o ciclo de vida da empresa, por não se encontrar fatos ou fontes de evidência referentes a possível estagnação no mercado de atuação ou mesmo em seus indicadores de rentabilidade e demonstrações financeiras, assim como nenhuma intenção de liquidação de segmento de negócios, aversão a risco ou crescimento lento e baixo nível de inovação.

Quanto à estrutura organizacional, leva-se em conta que, conforme a empresa avança nos quatro primeiros estágios, demanda maior sofisticação e desenvolvimento de processamento de informações, formalização nos controles, monitoramento das atividades e progressiva descentralização nas decisões estratégicas (Miller, \& Friesen, 1984).

As variáveis referentes às estratégias, durante as fases do CVO, são inovação e diversificação de produtos e serviços com predominância nas fases do Crescimento e Renovação. Durante a Maturidade é esperado maior enfoque e eficiência nos recursos já conquistados (Miller, \& Friesen, 1984).

Na tomada de decisão, há a consideração de que, conforme a empresa cresce em tamanho e torna as atividades administrativas mais complexas, há maior necessidade e uso de instrumentos na análise e consideração de outros pontos de vista, e integração das decisões entre as diferentes áreas, sendo maior na fase da Renovação e em menor nível na Maturidade (Miller, \& Friesen, 1984). Com isso, o quadro 5 demonstrada no tópico do Estudo de Caso foi construída com a classificação dos períodos do ciclo de vida da empresa.

\section{ESTUDO DE CASO}

Conforme os dados coletados e comparados com a literatura prévia, a empresa foi classificada nos estágios, conforme resumido no quadro 5, que tem por objetivo relacionar a linha do tempo da organização com as etapas do CVO. Na análise de suas características, dois períodos destacam-se 
como os subestágios: i.) entre o Crescimento e a Maturidade ii.) e da Maturidade para a Renovação, onde identificou-se aspectos relevantes de mudanças no SCG.

Esses períodos trazem características mistas da empresa em relação à situação, estrutura, estratégia e estilo de tomada de decisões e são marcados por ações internas que influíram na transição para o estágio seguinte, como a implementação de mecanismos, maior informatização de processos, trazendo maior número de informações gerenciais na análise e tomada de decisão.

Quadro 5- Classificação da Organização nos Estágios do Ciclo de Vida Organizacional

\begin{tabular}{|c|c|c|}
\hline & rganizacional & Estratégias e Estilo de Tomada de decisão \\
\hline & & $\begin{array}{l}\text { contro de nicho de mercado. Alta inovação em } \\
\text { dutos (de cursinho a Ensino Superior). } \\
\text { escimento para cerca de } 1.500 \text { alunos (1975). } \\
\text { co substancial. }\end{array}$ \\
\hline & $\begin{array}{l}\text { aior que na fase anterior. Consolidada em } \\
\text { rmos de produto e mercado. } \\
\text { ecisões centralizadas nos associados. }\end{array}$ & de alunos para cerca de 2.800 alun \\
\hline \multirow{2}{*}{$\begin{array}{l}\text { Subestágio de } \\
\text { Transição - } \\
\text { (Crescimento à } \\
\text { Maturidade): } \\
\text { (1993 - 2002) } \\
\text { Status de } \\
\text { Universidade }\end{array}$} & \multirow{2}{*}{\multicolumn{2}{|c|}{$\begin{array}{l}\text { Ambiente mais competitivo e heterogêneo. Abertura de cargos profissionais na gestão acadêmica. } \\
\text { Criação do Conselho de Administração. Plano de sucessão e mudanças na estrutura societária } \\
\text { (2001). Expansão de cursos e unidades: cerca de } 10.000 \text { alunos (2001). } \\
\text { Mudanças no SCG: Formalização da Missão e Visão. Início de desenvolvimento de relatórios de } \\
\text { controles de despesas e capex. Informatização nos controles acadêmicos. Internalização da área de } \\
\text { contabilidade. Implantação de Sistema integrado de informações. Acompanhamento de } \\
\text { indicadores acadêmicos para avaliação de desempenho. }\end{array}$}} \\
\hline & & \\
\hline & & $\begin{array}{l}\text { Acom } \\
\text { Profis } \\
\text { Centra }\end{array}$ \\
\hline \multirow{2}{*}{$\begin{array}{l}\text { Subestágio de } \\
\text { Transição: }(2008 \\
-2010)\end{array}$} & \multicolumn{2}{|c|}{$\begin{array}{l}\text { Ambiente dinâmico e competitivo. Primeiras concorrentes abrem capital. Contratação do primeiro } \\
\text { diretor financeiro estatutário. }\end{array}$} \\
\hline & \multicolumn{2}{|c|}{$\begin{array}{l}\text { Mudanças no SCG: Aumento de formalização e profissionalização: Implantações - Planejamento } \\
\text { Estratégico; Orçamento base zero; Ampliação do Sistema de Remuneração e Recompensas. } \\
\text { Mudança no escopo dos relatórios orçamentários. }\end{array}$} \\
\hline ior ênf & $\begin{array}{l}\text { estrutura de capital com aporte de sócios } \\
\text { vestidores e para sociedade anônima. } \\
\text { uito grande. Crescimento exponencial } \\
8.000,2012 \text {, para } 160.000 \text { alunos, 2016). }\end{array}$ & $\begin{array}{l}\text { para c } \\
\text { Maior } \\
\text { invest } \\
\text { financ }\end{array}$ \\
\hline
\end{tabular}

Fonte: Os autores

Nascimento: nesse período, a empresa era um pequeno negócio, os donos coordenavam diretamente todos os funcionários e não havia formalização de planejamento conforme as características típicas deste estágio, segundo Churchill e Lewis (1983), autores do modelo de CVO para empresas de pequeno porte.

Crescimento: conforme Miller e Friesen (1984) nessa fase, a empresa já é um pouco maior que na fase anterior, porém ainda centralizada nos donos e familiares, contando com um número limitado de empregados. Representa o período em que a empresa já se estabilizou no mercado, de forma distinta, com suas competências particulares e demonstração da potencialidade do negócio, a empresa que começou com um cursinho já experimentava ampliação de cursos em várias modalidades, incluindo ensino superior.

O uso de informações gerenciais era mínima, resumindo-se a controle de caixa e aplicações financeiras (Chrchill, \& Lewis, 1983). Esses resultados vão opostos ao estudo de Moores e Yuen 
(2001) que encontraram maior formalização e uso de informações gerenciais no estágio do crescimento. O próprio modelo de Miller e Friesen (1984) prevê uma estrutura mais descentralizada no Crescimento, com maior formalização e processamento de informações.

No entanto, conforme fragmento: "A gente sempre esteve atento ao contexto de mercado, [...] mas não de uma forma estruturada, e sim informal. [...] Antes precisava crescer, era na intuição e sempre visando um retorno de longo prazo." (Diretor de Desenvolvimento). Com isso, observa-se que a gestão da empresa se dava de modo intuitivo e informal, e o desenvolvimento foi possível devido ao mercado favorável e à crescente demanda por cursos, o foco era a busca por alunos e geração de receitas para sustentar a viabilidade do negócio (Lester, Parnell, \& Carraher, 2003; Miller, \& Friesen, 1984).

Subestágio do Crescimento para a Maturidade: nesse período, a empresa apresentava algumas características da Maturidade como porte suficiente e razoável penetração de mercado para continuar as suas atividades em expansão de forma rentável, sustentável e competitiva (Miller, \& Friesen, 1984). No entanto, verifica-se nesse período de transição, dois fatores importantes: crise no modelo de gestão, o que incorreu no processo de sucessão e início de profissionalização.

No ambiente das empresas, especialmente a familiar, conflitos internos podem ocorrer, e surgir crises propulsoras para mudanças (Greiner, 1998). No caso, conforme exemplificado no fragmento abaixo, resultou na saída de 2 associados que eram irmãos entre si que, até então, compunham a terceira família na época, quando eram quatro fundadores remanescentes.

Além disso, diversos outros familiares trabalhavam tanto nas áreas acadêmicas, como administrativas e houve a necessidade de reorganizações. Nesse processo, foram planejados e estabelecidos o processo de sucessão e houve contratação de profissionais externos para reitoria pela primeira vez. A gestão operacional da área acadêmica começou a ser feita através das reitorias e próreitorias por profissionais externos das famílias.

"Certamente, a gente teve um momento de crise, e aguda, eu diria, entre 2000 e 2001, que foi justamente na implantação de um novo modelo, todos os sócios participaram do planejamento do novo modelo, todo mundo concordou, porque era uma mudança importante, porque previa inclusive a saída de alguns membros da família da gestão, [...] e contratamos duas consultorias que nos ajudaram a construir esses modelos. A sociedade cindiu na implantação, teve um desacordo, dois dos quatro (associados), que eram irmãos entre si, saíram da sociedade." (Diretor de Desenvolvimento).

Ademais, o sistema de informações não era integrado e a contabilidade era desenvolvida fora da empresa, mediante recurso externo, as informações não eram frequentes, sem resultados por departamento ou centro de custos, recursos esperados para a fase da Maturidade, de modo a manter o gerenciamento de forma efetiva das competências e habilidades (Greiner, 1998; Miller, \& Friesen, 1984).

Para entrar no estágio da Maturidade de Miller e Friesen (1984) equivalente a "Direção" de Greiner (1998), havia então de se melhorar e ampliar o sistema de controle gerencial para manter o foco na estabilidade com eficiência. Conforme Churchill e Lewis (1983), nessa fase, o papel dos donos deve ser mais no gerenciamento do que no operacional, ou a empresa pode ficar em modo de sobrevivência (Scott, \& Bruce, 1987).

Observa-se que conforme Giovannoni, Maraghini e Riccaboni (2011), o processo de sucessão na empresa familiar abre oportunidade para mudanças e profissionalização dos processos e tem impacto na definição do CVO e na mudança dos controles gerenciais. Com isso, a crença e envolvimento dos proprietários nesses projetos é fundamental na institucionalização dos controles gerenciais (Churchill \& Lewis, 1983).

As principais ações que contribuíram para a instituição avançar para o estágio da Maturidade, foram estruturação das funções de Controladoria, onde começaram a ser desenvolvidos relatórios para projeções e alocações por departamento e centros de custos, no que tange a despesas e planejamento 
de CAPEX (Capital Expenditure) com acompanhamento entre estimado e realizado. Essas informações eram importantes, visto que para a empresa que procurava expandir, os investimentos em ativo imobilizado são relevantes, o ambiente era mais competitivo e era necessário esse controle, ainda que focado mais no curto prazo do que no longo prazo (Miller, \& Friesen, 1984).

Nessa fase, também já havia acompanhamento de indicadores referentes a qualificação da área acadêmica, visto que a Universidade precisa atender requisitos mínimos para credenciamento e manutenção dos cursos, pois são acompanhados pelo órgão regulador, impactando também na reputação da Instituição.

Maturidade: nessa fase, a empresa apresenta certa estabilidade com monitoramento de algumas informações que dão suporte às operações, com crescimento contínuo, acompanhamento das oportunidades e imitação da concorrência, o que é uma característica quando a empresa está nessa fase, com tamanho maior do que nas fases anteriores e aumento do mercado de atuação, porém com menor diversificação e menor grau de risco conforme Miller e Friesen (1984).

A Contabilidade já estava internalizada, contudo, o sistema de controle gerencial ainda não era pleno, não havia planejamento estratégico e as informações para tomada de decisões não eram tempestivas. Conforme fragmento: "Não tinha uma organização formal, nos aspectos do porte da empresa. Tinha sistema financeiro integrado com o acadêmico, contabilidade interna, mas o balanço demorava para sair [...] O rolling forecast existe desde 2008, com a implantação do orçamento base zero". (Diretor Financeiro).

Esse é contraponto com os modelos tradicionais de CVO, onde se espera maior controle de custos, uso do orçamento e controle das variações entre orçado e realizado (Greiner, 1989; Miller, \& Friesen, 1984; Lester, Parnell, \& Carraher, 2003). Na empresa familiar, mesmo durante a etapa da Maturidade, a formalização dos processos e o uso sistemático de mecanismos pode ser diferente da empresa não familiar, pois variam de acordo com as necessidades das famílias controladoras (Hiebl, 2012; Moores, \& Mula, 2000).

Subestágio da Maturidade para a Renovação: a partir de 2007, as primeiras empresas do setor começam abrir capital, e almejando expandir-se e aproveitar o momento de mercado, a empresa volta a fazer aquisições relevantes iniciando-se um novo marco:

"Em 2008, também tem um outro marco [...] uma mudança substancial nos nossos controles, que aí a gente trouxe o (Diretor Financeiro Atual) que mudou todo o sistema gerencial aqui, quer dizer, remodelou completamente toda a estrutura de gerencial, porque a gente ia passar para outros volumes." (Diretor de Desenvolvimento, Família A).

Le Breton-Miller e Miller (2013) argumentam que, conforme as empresas desejam transitar pelos ciclos evolucionários, podem ser desafiadas quanto a recursos que podem ser críticos para o crescimento, como financeiro e suporte técnico. Com isso, veio a necessidade de sofisticar ainda mais os controles em inovações que se provaram necessárias para atuar nesse novo cenário.

Essa tendência vai ao encontro da literatura de que, quando as empresas familiares se tornam maiores e mais velhas, a tendência é a contratação de um diretor financeiro profissional (Hiebl, 2013), especialmente quando não há familiares disponíveis para preencher a posição com responsabilidades e habilidades específicas demandadas pela área financeira. A contratação de profissional não familiar também é necessária para continuidade dos negócios, trazendo maior grau de decisões analíticas e racionais, diminuindo o perfil intuitivo de tomada de decisão das empresas familiares.

O papel do novo diretor financeiro foi de inclusão de maiores ferramentas para análise das informações, com mudança na frequência e escopo dos relatórios gerenciais e formalização do planejamento estratégico (business plan), além da implantação do orçamento base zero: "Em 2008 e 2009 estávamos arrumando a casa." (Diretor Financeiro).

"A gente tinha estimativa de orçamento para o ano seguinte, esse ano vai ter tanto de reajuste, deve ter tanto de ingresso, o dissídio deve ser tanto... estimativa geral de receitas e despesas e mais ou menos o Capex. A lei obrigava ter controle por centros, depois por departamento, 
hoje é olhado por curso. Mas, era sem método de custeio, tudo era despesa. A contabilidade foi melhorada com as primeiras listadas a publicar balanço" (Diretor de Desenvolvimento).

"Os controles eram bons, no entanto, um pouco atrasada em relação à concorrência para abertura de capital, precisava tornar-se atrativa para a entrada de sócios investidores" (Diretor Financeiro).

Conforme os fragmentos acima, observa-se um período dinâmico de transição com impactos no SCG que vinha como resposta a uma possível crise com a entrada de novos competidores. A empresa optou por se preparar para a possível abertura de capital ou ficar mais atrativa ao aporte de capital de sócio investidor. Essas mudanças estão de acordo com Silvola (2008), que encontrou maior sofisticação dos controles gerenciais em fases em que há maior diversificação na estrutura de capital, como a Renovação, devido a maior necessidade de prestação de contas a investidores. Com isso, a empresa entrou num novo ciclo, o da Renovação, onde era esperado um período de expansão e diversificação.

Renovação: desde 2011, a empresa apresenta as características da Renovação com alta inovação e diversificação de cursos, crescimento através de aquisições relevantes (Miller e Friesen, 1984), e os sistemas de controle gerencial são altamente sofisticados e abrange todos os níveis do Sistema de Controle Gerencial de Malmi e Brown (2008) dando suporte as operações (Greiner, 1998; Miller e Friesen, 1984) com planejamento estratégico, controles cibernéticos com elaboração e acompanhamento do orçamento e indicadores financeiros e não financeiros e sistema de remuneração e recompensas.

\subsection{O Sistema de Controle Gerencial}

No quadro 6, os mecanismos com base no modelo de SCG de Malmi e Brown (2008) são elencados no que tange Planejamento, Controles Cibernéticos e Sistema de Remuneração e Recompensa relacionados com os estágios do CVO. A análise dos controles cultural e administrativo são incluídos no final desta seção.

Conforme a análise dos ciclos evolucionários do caso e o sistema de controle gerencial, observam-se as seguintes configurações:

Nascimento: como especificado na literatura forte intervenção da família e ausência de um sistema de controle gerencial formal. Tanto pelo momento do negócio como da empresa ter foco no crescimento do negócio.

Crescimento: ampliação do negócio sem base estruturada de informações, o crescimento é sustentado pela viabilidade do negócio, controle cultural através da centralização do processo decisório.

Subestágio de transição para maturidade: o crescimento e o processo de sucessão abrem oportunidade para a profissionalização de processos e a agregação de profissionais de fora da família. Essas mudanças provocaram a necessidade de maior estruturação da organização, o que não acontece instantaneamente mais paulatinamente, com impactos no SCG e na transição para o próximo estágio do CVO.

Maturidade: encontramos maior formalização e processamento de informações gerenciais, o que possibilitou a empresa ter controle mais efetivo nessa fase. Ao mesmo tempo que existe uma menor centralização operacional, a centralização das decisões estratégicas é muito forte e o uso de mecanismos do SCG ainda não é pleno.

Subestágio para a Renovação: o que mais chama a atenção neste momento é que existe o aperfeiçoamento de mecanismos que, de alguma forma, já existiam e a ampliação do SCG, juntamente com a contratação de um executivo financeiro profissional. Refere-se ao modelo de planejamento estratégico, orçamento base zero sendo discutido no lugar do mecanismo tradicional e aumento no escopo do sistema de relatórios, por exemplo. Com isso, este período de transição e implantação de controles possibilitou a empresa transitar para o estágio seguinte da Renovação. 
Renovação: o aspecto mais destacado é a presença do investidor externo que vem com o seu modelo de gestão e demanda ajustes no modelo de gestão organização. Ênfase no uso do sistema de relatórios gerenciais e redução de tomada de decisão no modelo intuitivo é o exemplo mais flagrante.

\begin{tabular}{|c|c|c|c|}
\hline Estágio & $\begin{array}{c}\text { Planejamento } \\
\text { Estratégico Formal } \\
\end{array}$ & Controles Cibernéticos & Sistema de avaliação e recompensa \\
\hline Nascimento & Inexistente & Inexistente & Inexistente \\
\hline Crescimento & Inexistente & Inexistente & Inexistente \\
\hline $\begin{array}{l}\text { Subestágio de } \\
\text { Transição } \\
(1993-2002)\end{array}$ & Inexistente & $\begin{array}{l}\text { Desenvolvimento de relatórios com } \\
\text { estimativas de despesas e orçamento de } \\
\text { capital e controle orçamentário. } \\
\text { Estabelecimento de metas através de } \\
\text { indicadores. }\end{array}$ & Inexistente \\
\hline $\begin{array}{l}\text { Maturidade } \\
(2003-2008)\end{array}$ & Inexistente & $\begin{array}{l}\text { Orçamento para despesas e capex. } \\
\text { Controle orçamentário. Monitoramento } \\
\text { de indicadores. }\end{array}$ & $\begin{array}{l}\text { Sistema de avaliação de desempenho } \\
\text { através do acompanhamento de } \\
\text { indicadores de desempenho. }\end{array}$ \\
\hline $\begin{array}{l}\text { Subestágio de } \\
\text { Transição } \\
(\mathbf{2 0 0 8}-\mathbf{2 0 1 0})\end{array}$ & $\begin{array}{l}\text { Institucionalização } \\
\text { do Planejamento } \\
\text { Estratégico (business } \\
\text { plan). }\end{array}$ & $\begin{array}{l}\text { Implementação do orçamento base } \\
\text { zero; Aumento no escopo do } \\
\text { orçamento e controle orçamentário; } \\
\text { Sistema de indicadores qualitativos e } \\
\text { quantitativos. }\end{array}$ & $\begin{array}{l}\text { Ampliação do sistema de avaliação e } \\
\text { recompensas. }\end{array}$ \\
\hline $\begin{array}{l}\text { Renovação } \\
(2011-2016)\end{array}$ & $\begin{array}{l}\text { Planejamento } \\
\text { Estratégico. Análise } \\
\text { de cenários, riscos e } \\
\text { retornos sobre } \\
\text { investimentos. }\end{array}$ & $\begin{array}{l}\text { Orçamento anual e demonstrações } \\
\text { financeiras projetadas. } \\
\text { Controle orçamentário mensal e } \\
\text { análise das variações. } \\
\text { Acompanhamento de indicadores } \\
\text { financeiros e não financeiros. }\end{array}$ & $\begin{array}{l}\text { Sistema de remuneração baseada em } \\
\text { metas e indicadores a partir de nível } \\
\text { de gerência, e na área acadêmica a } \\
\text { partir de cargo de coordenadores de } \\
\text { cursos. }\end{array}$ \\
\hline
\end{tabular}

Fonte: Os autores

Controles Administrativos: por ser uma empresa regulada pelo Ministério da Educação, os controles administrativos sempre estiveram presentes na área Acadêmica. Conforme a empresa foi evoluindo nos estágios evolucionários, os controles administrativos aumentaram-se gradativamente incluindo normas, políticas e procedimentos para aprovação de verbas por exemplo, manuais, código de ética, além da área de auditoria interna e compliance.

Controle Cultural: é influenciado tanto por mudanças estruturais que provocam adaptações de comportamentos nos diversos níveis, como também a postura proativa da gestão reflete adaptação cultural a priori quanto às necessidades de mudanças nos SCG para se alcançar os objetivos durante as transições de estágios do CVO.

Até a fase da Maturidade, a gestão era de modo intuitivo, o papel do controle cultural é influenciado pelos valores, empreendedorismo e identificação dos fundadores com a empresa, com o compartilhamento dos objetivos entre associados e familiares, comprometimento e realização pessoal através do negócio, influenciando os envolvidos nas ações de médio prazo e longo prazo no destino da empresa. Esse é um fator intangível no sucesso de algumas empresas familiares (Donnelley, 1964), podendo ocorrer sacrifício financeiro, e retornos mínimos, conforme fragmentos abaixo:

"E meu pai, ele sempre privilegiou o reinvestimento, os prédios construídos, foram tudo caixa da instituição, reinvestimento direto." (Diretor de Desenvolvimento, Família A).

"Tudo era reinvestido, senão não teríamos crescido desta forma" (Sócio fundador B, do livro comemorativo de 30 anos da instituição).

No subestágio para a Maturidade, a Missão e a Visão da empresa foram formalmente escritos, influenciando todos os envolvidos e causando mudanças culturais, por conta de seguimento de padrões de metas de desempenho para atender às exigências de órgão regulador para o 
credenciamento como Universidade. Aqui, os controles administrativos também são ampliados com normas e regimentos e entra também a preocupação com a reputação da instituição. Isso influencia em novos perfis de contratação e adaptação do corpo docente por exemplo.

Já na transição para a Renovação, há mudanças na estrutura de governança com a entrada de sócios investidores. Surgem então novos "atores" fora do círculo familiar com direitos de exercer alguma influência ou controle na direção estratégica da empresa (Gomez-Mejia, Makri, \& Kintana, 2010), trazendo maior ênfase na prestação de contas (accountability) e busca por resultados financeiros, esse momento traz impacto cultural na organização e requer adaptação nos diversos níveis, conforme reflexão da funcionária: "Mudanças são necessárias, senão não acompanha, não pode ficar estagnado, ganha-se algumas coisas, perde-se outras. (Analista de Controladoria).

$\mathrm{Na}$ Renovação, verifica-se que a profissionalização, com o uso intensivo das informações, análise de riscos e retornos sobre o investimento de forma sistemática dão lugar ao perfil empreendedor, restringindo ainda mais o perfil intuitivo das fases anteriores, conforme fragmentos: "A gente sabia que tinha que tinha que ir... tomar posição, não era de fazer muita conta... [...] Quando trouxe alguém que é cabeça financeira, trouxe outro nível para a empresa, que era de multinacional, foi um marco bastante importante". (Diretor de Desenvolvimento).

Outra questão importante do SCG refere-se à ampliação do sistema de remuneração e recompensa que, segundo Malmi e Brown (2008) tem impacto no controle cultural, pois funciona no alinhamento dos comportamentos e encorajamento para alcance dos objetivos: "A gente tem aproximadamente uns 300 indicadores e cobre várias das áreas. Tem remuneração baseada nos indicadores $[\ldots]$ bem críticas e detalhadas". (Diretor Financeiro).

Por fim, apesar das mudanças na situação e estrutura da empresa ao longo dos anos, a mesma continua sendo percebida como "empresa familiar", conforme fragmento da entrevista: "O fundo não alterou o projeto de longo prazo, os valores, a essência. Eles enxergam isso, veem valor nisso, senão tira a essência”. (Diretor de Desenvolvimento). Com isso, aparentemente, a influência da família é muito forte, influenciando os envolvidos e indivíduos nos mais diversos níveis da organização.

\section{CONCLUSÕES}

O sistema de controle gerencial é fundamental para a gestão das organizações e, particularmente nas empresas familiares, a sua configuração pode ser diferenciada pelas peculiaridades deste tipo de organização. Com isso, este estudo teve como objetivo analisar a evolução e o papel do SCG junto às transições de estágios no CVO em uma empresa familiar, através da visão dos antecedentes, circunstâncias, motivações e as consequências das mudanças.

Os achados da pesquisa estão de acordo com estudos anteriores quanto à necessidade de formalização de controles gerenciais conforme a empresa passa para os estágios mais avançados (Moores, \& Mula, 2000; Moores, \& Yuen, 2001). Porém, esta pesquisa teve abordagem longitudinal e teve dois principais achados: primeiro, que a transição de uma etapa para outra não é automática e pode levar um período de transição que depende da gestão em tomar ações para viabilizar a passagem de estágios e segundo que o SCG pode ter um papel durante os passagens entre as etapas do CVO, marcados por mudanças estruturais e implementação de mecanismos, controles e artefatos da Contabilidade Gerencial que contribuíram para a empresa possuir as características requeridas para serem classificadas no estágio seguinte.

Com isso, este estudo de caso complementa as outras variáveis dos estudos empíricos e modelos, ao capturar os períodos de transição, nos quais denominamos de subestágios. Nos subestágios identificados, observou-se momentos de reorganizações na estrutura e crescente profissionalização para atender os anseios de crescimento e expansão, nos quais foram enfatizadas a necessidade de ampliação do SCG.

Especificamente, o papel do SCG contribuiu tanto para atender a demanda de informações gerenciais internas nos processos de planejamento e controle derivados do aumento de volume que 
viriam com a Maturidade e Renovação, como para a prestação de contas e tomada de decisões mais analítica devido a entrada de investidores externos à família no estágio da Renovação.

Para a transição de um estágio a outro, mudanças são necessárias, as quais se não atendidas, a empresa poderia ficar em modo de sobrevivência. A velocidade das mudanças, no entanto, depende tanto de fatores externos como internos (Scott, \& Bruce, 1987) ou seja, das necessidades percebidas pelos gestores e administradores das empresas familiares, dependendo do contexto organizacional, incluindo a crença e adaptação cultural.

No caso, a plenitude do SCG como pacote é encontrada somente na fase da Renovação, que tem como característica expansão de produto e mercado, entrada de sócios investidores que trazem maior perspectivas de resultados para o curto prazo e maiores análises no processo de planejamento, controle e tomada de decisão. Nessa fase, o SCG fornece à empresa suporte para a análise de riscos e oportunidades, monitoramento de resultados e desempenhos com maior abrangência no escopo e frequência dos relatórios gerenciais, incluindo o sistema de remuneração e recompensa.

Todas essas mudanças têm impacto cultural conforme a organização evolui do SCG com maior presença de mecanismos informais para formais. Apesar disso, na empresa de controle familiar, os valores e história das famílias controladoras sobrepostas a construção e evolução da empresa fazem parte do dia a dia da empresa e influenciam no controle cultural e permanecem como referência entre os indivíduos.

Quanto às limitações deste estudo, como se baseia em eventos de forma retrospectiva no tempo, contando com documentos e relatos sobre fatos e estágios de ciclo de vida passados, as datas e os números de alunos podem não ser tão precisos. O histórico de eventos pode variar, para isso foram analisadas diversas fontes, de forma a combinar os dados e apropriar os eventos relevantes nos períodos distribuídos no tempo.

A combinação de fatores internos e externos varia de uma empresa a outra, de um setor a outro. Sugere-se, para pesquisas futuras, incluir outras empresas familiares em termos de porte e setor; também seria interessante a comparação em estudos de caso múltiplos com empresas similares durante o mesmo período e análise de adoção do SCG e as consequências nos estágios de CVO, assim como casos onde pode ser analisada as circunstâncias de abandono de controles e a relação com o estágio de declínio,

\section{REFERÊNCIAS}

Acquaah, M. (2013). Management control systems, business strategy and performance: A comparative analysis of family and non-family businesses in a transition economy in sub-Saharan Africa. Journal of Family Business Strategy, 4(2), 131-146.

Ahrens, T., \& Chapman, C. S. (2006). Doing qualitative field research in management accounting: positioning data to contribute to theory. Accounting, Organizations and Society, 31(8), 819-841.

Auzair, S. M., \& Langfield-Smith, K. (2005). The effect of service process type, business strategy and life cycle stage on bureaucratic MCS in service organizations. Management Accounting Research, 16(4), 399-421.

Beuren, I. M., \& Pereira A. M. (2013). Ciclo de vida organizacional e controles de gestão: análise da produção científica em periódicos nacionais e internacionais. Review of Administration and Innovation, 10(2), 123-143.

Beuren, I. M., Rengel, S., \& Rodrigues Junior, M. M. (2015). Relação dos atributos da contabilidade gerencial com os estágios do ciclo de vida organizacional. Revista Innovar, 25(57).

Carney, M. (2005). Corporate governance and competitive advantage in family-controlled firms. Entrepreneurship \& Regional Development, 29, 249-265.

Carvalho, K. L., Saraiva Júnior, A. F., Frezatti, F., \& Costa; R. P. (2010). A contribuição das teorias do ciclo de vida organizacional para pesquisa em contabilidade gerencial. Revista de Administração Mackenzie, 11(4), 98-130.

Chenhall, R. H. (2007). Theorizing contingencies in management control systems research. Handbooks of Management Accounting Research, 1, 163-205. 
Chrisman, J. J., Chua, J. H., \& Sharma, P. (2005). Trends and directions in the development of a strategic management theory of the family firm. Entrepreneurship theory and practice, 29(5), 555-576.

Chua, J. H., Chrisman, J. J., \& Massis, A. (2015). A closer look at socioemotional Wealth: Its Flows, Stocks, and Prospects for Moving Forward. Entrepreneurship: Theory and Practice, 39(2), 173-182.

Churchill, N. C., \& Lewis, V. L. (1983). The five stages of small business growth. Harvard Business Review, 61(3), 30-50.

Cooper, D. J., \& Morgan, W. (2008). Case study research in accounting. Accounting Horizons, 22(2), 159178.

Cunha, P. R., Klan, R. C., \& Lavarda, C. E. F. (2013). Ciclo de vida organizacional e controle gerencial: uma análise de artigos em periódicos internacionais de contabilidade. Revista de gestão, finanças e contabilidade, 3(3), 170-186.

Dawson, A., \& Mussolino, D. (2014). Exploring what makes family firms different: discrete or overlapping constructs in the literature? Journal of Family Business Strategy, 5(2), 169-183.

De Massis, A., \& Kotlar, J. (2014). The case study method in family business research. Academy of Management Review, 14(4), 532-550.

Dekker, J. C., Lybaert, N., Steijvers, T., Benoît, D., \& Mercken, R.. (2012). Family firm types based on the professionalization construct: exploratory research. Family Business Review, 26(1), 81-99.

Donnelley, R. G. (1964). The family business. Harvard Business Review, 42(4), 93-105.

Dyck, B., Mauws, M., Starke, F. A., \& Mischke, G. A. (2002). Passing the baton the importance of sequence, timing, technique and communication in executive succession. Journal of Business Venturing, 17(2), 143-162.

Faveri, D. B., Cunha, P. R., Santos, V., \& Leandro, D. A. (2014). Relação do ciclo de vida organizacional com o planejamento: um estudo com empresas prestadoras de serviços contábeis do estado de Santa Catarina. REPEC - Revista de Educação e Pesquisa em Contabilidade, 8(4), 382-402.

Ferreira, A., \& Otley, D. (2009). The design and use of performance management systems: an extended framework for analysis. Management Accounting Research, 20(4), 263-282.

Frezatti, F., Relvas, T. R. S., Nascimento, A. R., Junqueira, E. R., \& Bido, D. S. (2010). Perfil de planejamento e ciclo de vida organizacional nas empresas brasileiras. Revista de Administração, 45(4), 383-399.

Giovannoni, E., Maraghini, M. P., \& Riccaboni, A. (2011). Transmiting knowledge across generations: The role of management accounting practices. Family Business Review, 24(2), 126-150.

Granlund, M., \& Taipaleenmäki, J. (2005). Management control and controllership in new economy firms - a life cycle perspective. Management Accounting Research, 16(1), 21-57.

Gomez-Mejia, L. R., Makri, M., \& Kintana, M. L. (2010). Diversification decisions in family-controlled firms. Journal of Management Studies, 47(2), 223-252.

Greiner, L. (1998). Evolution and revolution as organizations grow. Harvard Business Review, 76(3), 55-68.

Hiebl, M. R. W. (2012). Peculiarities of financial management in family firms. International Business \& Economics Research, 11(3), 315-323.

Hiebl, M. R. W. (2013). Bean counter or strategist? Differences in the role of the CFO in family and nonfamily businesses. Journal of Family Business Strategy, 4(2), 147-161.

Ifera. (2003). Family businesses dominate. Family Business Review, 16(4), 235-240.

Kallunki, J-P., \& Silvola, H. (2008). The effect of organizational life cycle stage on the use of activity-based costing. Management Accounting Research, 19(1), 62-79.

Kalm, M., \& Gomez-Mejia, L. R. (2016). Socioemotional wealth preservation in family firms. Revista de Administração, 51(4), 8-10.

Klann, R. C., \& Klann, P. A., Postal, K. R., \& Ribeiro, M. J. (2012). Relação entre o ciclo de vida organizacional e o planejamento em empresas metalúrgicas do Município de Brusque-SC. RCO Revista de Contabilidade e Organizações, 6(16), 120-142.

Lavanda, C. E. F., \& Pereira A. M. (2012). Uso dos sistemas de controles de gestão nas diferentes fases do ciclo de vida organizacional. Revista Alcance, 19(4), 497-518.

Le Breton-Miller, I., \& Miller, D. (2013). Socioemotional wealth across the family firm life cycle: A commentary on "family business survival and the role of boards." Entrepreneurship: Theory and Practice, 37(6), 1391-1397.

Lester, D. L., \& Parnell, J. A. (2008). Firm size and environmental scanning pursuits across organizational life cycle stages. Journal of Small Business and Enterprise Development, 15(3), 540-554. 
Lester, D. L., Parnell, J. A., \& Carraher, S. (2003). Organizational life cycle: a five-stage empirical scale. The Internatonal Journal of Organizational Analysis, 11(4), 339-354.

Malmi, T., \& Brown, D. A. (2008). Management control systems as a package-opportunities, challenges and research directions. Management Accounting Research, 19(4), 287-300.

Marques, K. C. M., Camacho, R. R., \& Alcantara, C. C. V. (2015). Assessment of the methodological rigor of case studies in the field of management accounting published in Journals in Brazil. Revista Contabilidade \& Finanças, 26(67), 27-42.

Martins, G. A., \& Theóphilo, C. R. (2009). Metodologia da investigação científica para ciências sociais aplicadas. 2.ed. São Paulo: Atlas.

Miller, D., \& Friesen, P. H. (1984). A longitudinal study of the corporate life cycle. Management Science Journal, 30(10), 1161-1183.

Moores, K., \& Mula, J. (2000). The salience of market, bureaucratic and clan controls in the management of family firm transitions: some tentative Astralian Evidence. Family Business Review, 13(2), 91-106.

Moores, K., \& Yuen, S. (2001). Management accounting systems and organizational configuration: a lifecycle perspective. Accounting, Organization and Society, 26, 351-389.

Morris, M. H., Williams, R. O., Allen, J. A., \& Avila, R. A. (1997). Correlates in family of success business transitions. Journal of Business Venturing. 6(x), 385-401.

Necyk, G. A., \& Frezatti, F. (2010). A Contabilidade Gerencial: uma perspectiva de ciclo de vida de seu desenvolvimento nas organizações. Organizações \& Sociedade. 17(55), 725-744.

Prencipe, A., Bar-Yosef, S., \& Dekker, H. C. (2014). Accounting research in family firms: theoretical and empirical challenges. European Accounting Review, 23(3), 361-385.

Quinn, R., \& Cameron, K. (1983). Organizational life cycles and shifting criteria of effectiveness. Management Science, 29(1), 33-51.

Scott, M., \& Bruce, R. (1987). Five Stages of Growth in Small Business. Long Ranging Planning, 20(3), 4552.

Silvola, H. (2008). Do organizational life-cycle and venture capital investors affect the management control systems used by the firm? Advances in Accounting, 24(1), 128-138.

Simons, R. (1995). Levers of control: how managers use innovative systems to drive strategic renewal. Boston: Harvard Business School Press.

Songini, L., Gnan, L., \& Malmi, T. (2013). The role and impact of accounting in family business. Journal of Family Business Strategy, 4(2), 71-83.

Souza, B. C., Necyk, G. A., \& Frezatti, F. (2008). Ciclo de vida das organizações e a contabilidade gerencial. Enfoque: Reflexão Contábil, 27(1), 9-22.

Su, S., Baird, K., \& Schoch, H. (2015). The moderating effect of organisational life cycle stages on the association between the interactive and diagnostic approaches to using controls with organisational performance. Management Accounting Research, 26, 40-53.

Tessier, S., \& Otley, D. (2012). A conceptual development of Simons'levers of control framework. Management Accounting Research, 23(3), 171-185.

Yin, R. K. (2014). Estudo de caso: planejamento e métodos 5.ed. Porto Alegre: Bookman. 